\title{
ESTUDO DA FORMAÇÃO DE VÓRTICES EM TOMADAS D’ÁGUA VERTICAIS UTILIZANDO A FUIDODINÂMICA COMPUTACIONAL (CFD)
}

\author{
Guilherme R. Mendes*, Laura Maria C. F. Fais.
}

\section{Resumo}

A tomada d'água é o órgão responsável por fazer a transição entre o escoamento livre e o forçado. Uma das dificuldades nos projetos de tomada d'água é a previsão da formação de vórtices, sendo que uma das condições para que a presença de vórtices no escoamento seja evitada é uma submergência mínima acima da tomada d'água, assim, este trabalho tem como objetivo a modelagem física e matemática do escoamento em tomadas d'água verticais para determinação da submergência crítica na formação de vórtices.

\section{Palavras-chave:}

vórtices, tomada d'água vertical, modelo físico.

\section{Introdução}

O escoamento com vorticidade pode trazer problemas, especialmente quando estes vem acompanhado do arraste de ar. Entre os problemas causados podem ser citadas a queda do rendimento de máquinas hidráulicas, a diminuição da vazão líquida e vibrações.

Várias pesquisas vêm sendo realizadas ao longo do tempo com o objetivo de avaliar a formação de vórtices em tomadas d'água. Dentre os autores, podem ser citados Ferreira (2001), Sarkadeh (2017), Fockert et. al. (2016), dentre outros.

Com o avanço das técnicas de modelação matemática, é possível também o estudo da formação de vórtices a partir de modelos matemáticos, o que permite um melhor entendimento do fenômeno e das variáveis que o afetam. É comum o uso da Fluidodinâmica Computacional (CFD) para o estudo do escoamento aliado ao estudo em modelos físicos para validação dos resultados.

Assim, este trabalho tem como objetivo avaliar a formação de vórtices em tomadas d'água verticais, tanto em modelo físico como matemático. Foi feito uma análise experimental em laboratório, e, posteriormente, realizado um estudo em modelo matemático utilizando o software de Mecânica dos Fluidos Computacional (CFD) CFX®).

\section{Resultados e Discussão}

O estudo em modelo físico foi realizado no banco de ensaio existente no Laboratório de Hidráulica e Mecânica dos Fluidos da FEC/Unicamp. Para as simulações computacionais será utilizado o software comercial de CFD ANSYS CFX® 16.0, com licença cedida FEQ/ Unicamp.

Foram realizados ensaios, com um tubo de $0,150 \mathrm{~m}$ de diâmetro, variando a submergência da tomada para avaliar a formação de vórtices, classificando-os de acordo com a sua intensidade. No Gráfico 1 mostra-se o tipo de vórtice formado para cada valor da relação S/D (sendo $S$ a submergência e $D$ o diâmetro da tomada). Nota-se que para valores menores de $S / D$, a intensidade dos vórtices aumenta.

Com o uso do software foi possível simular o escoamento na tomada. Na Figura 1 mostra-se 0 escoamento com formação de vórtice na tomada, com as vazões de ar arrastado

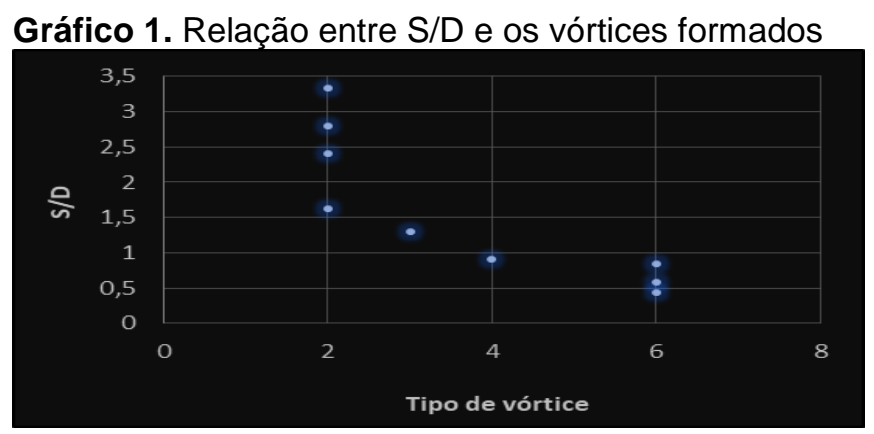

Figura 1. Arraste de ar gerado por um vórtice simulado

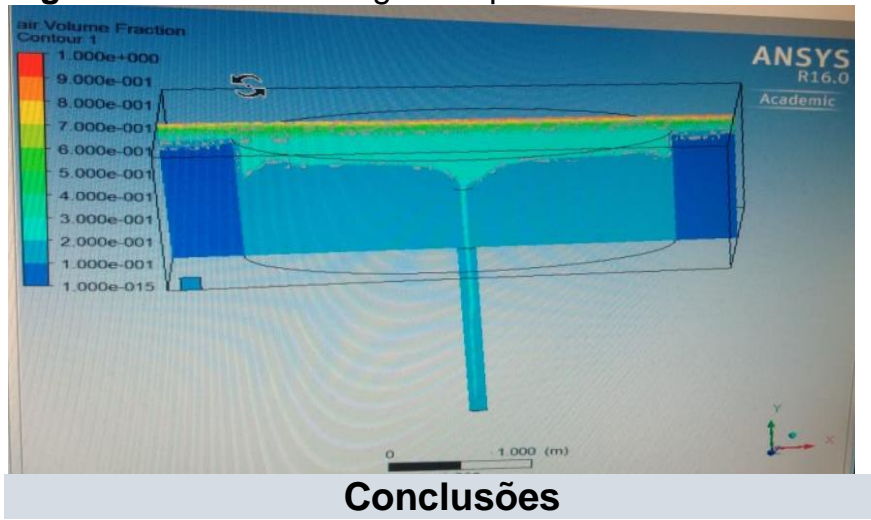

O software se mostrou útil para a modelagem, simulação e visualização de vórtices em tomadas d'água verticais, mostrando a formação de vórtices e seus efeitos, com boa concordância entre os resultados obtidos pelo modelo físico e matemático.

\section{Agradecimentos}

Ao Conselho Nacional de Desenvolvimento Científico e Tecnológico (CNPq) pela bolsa de Iniciação Científica. À FEQ/Unicamp, pela licença cedida.

FERREIRA, L.M.C. Submergência crítica na formação de vórtices em tomadas d'água verticais. Dissertação de mestrado. Universidade Estadual de Campinas, Campinas-SP, 2001.

FOCKERT, A., et al. Measuring swirl at a model scale of 1:1 for vertically submersible pumps. In: 28th Symposium on Hydraulic Machinery and Systems. Conf. Series: Earth and Environmental Science, 2016.

KIM, C.G. et. al. A study on the effectiveness of an anti vortex device in the sump model by experiment and CFD. In: $\mathbf{2 6}^{\text {th }}$ Symposium on Hydraulic Machinery and Systems. Conf. Series: Earth and Environmental Science, 2012.

SARKARDEH, H. Minimum Reservoir Water Level in Hydropower Dams. Chinese Mechanical Engineering Society and Springer-Verlag Berlin Heidelberg 2017. 